\title{
Uptake of dietary milk miRNAs by adult humans: a validation
}

\section{study [version 1; peer review: 3 approved]}

\author{
Amanda Auerbach1', Gopi Vyas', Anne Li¹, Marc Halushka(iD2, \\ Kenneth W. Witwer (D1,3 \\ ${ }^{1}$ Department of Molecular and Comparative Pathobiology, The Johns Hopkins University School of Medicine, Baltimore, MD, USA \\ 2Department of Pathology, The Johns Hopkins University School of Medicine, Baltimore, MD, USA \\ ${ }^{3}$ Department of Neurology, The Johns Hopkins University School of Medicine, Baltimore, MD, USA
}

\author{
V1 First published: 22 Apr 2016, 5:721 \\ https://doi.org/10.12688/f1000research.8548.1 \\ Latest published: 22 Apr 2016, 5:721 \\ https://doi.org/10.12688/f1000research.8548.1
}

\begin{abstract}
Breast milk is replete with nutritional content as well as nucleic acids including microRNAs (miRNAs). In a recent report, adult humans who drank bovine milk appeared to have increased circulating levels of miRNAs miR-29b-3p and miR-200c-3p. Since these miRNAs are homologous between human and cow, these results could be explained by xeno-miRNA influx, endogenous miRNA regulation, or both. More data were needed to validate the results and explore for additional milk-related alterations in circulating miRNAs. Samples from the published study were obtained, and 223 small RNA features were profiled with a custom OpenArray, followed by individual quantitative PCR assays for selected miRNAs. Additionally, small RNA sequencing (RNA-seq) data obtained from plasma samples of the same project were analyzed to find human and uniquely bovine miRNAs. OpenArray revealed no significantly altered miRNA signals after milk ingestion, and this was confirmed by qPCR. Plasma sequencing data contained no miR-29b or miR-200c reads and no intake-consistent mapping of uniquely bovine miRNAs. In conclusion, the results do not support transfer of dietary xenomiRs into the circulation of adult humans.
\end{abstract}

Keywords

Milk, miRNA, xenomiR, plasma, PBMC, diet, extracellular vesicles

\section{Open Peer Review}

\begin{tabular}{lccc} 
Approval Status & 1 & 2 & 3 \\
\hline & 1 & & \\
\hline version 1 & & & \\
22 Apr 2016 & view & view & view
\end{tabular}

1. Cherie Blenkiron, University of Auckland, Auckland, New Zealand

2. Jens Allmer iD, Izmir Institute of

Technology, Urla, Turkey

3. Hervé Seitz, French National Center for

Scientific Research (CNRS), Montpellier,

France

Any reports and responses or comments on the article can be found at the end of the article.

\footnotetext{
A This article is included in the Preclinical

Reproducibility and Robustness gateway.
} 
Corresponding author: Kenneth W. Witwer (kwitwer1@jhmi.edu)

Competing interests: No competing interests were disclosed.

Grant information: This work was supported by start-up funds from the Department of Molecular and Comparative Pathobiology (to KWW).

The funders had no role in study design, data collection and analysis, decision to publish, or preparation of the manuscript.

Copyright: @ 2016 Auerbach A et al. This is an open access article distributed under the terms of the Creative Commons Attribution License, which permits unrestricted use, distribution, and reproduction in any medium, provided the original work is properly cited.

How to cite this article: Auerbach A, Vyas G, Li A et al. Uptake of dietary milk miRNAs by adult humans: a validation study [version 1; peer review: 3 approved] F1000Research 2016, 5:721 https://doi.org/10.12688/f1000research.8548.1

First published: 22 Apr 2016, 5:721 https://doi.org/10.12688/f1000research.8548.1 


\section{Introduction}

Confirmation that microRNAs (miRNAs) from the diet, or dietary xenomiRs ${ }^{1}$, could be taken up into mammalian circulation and influence gene expression in the ingesting organism would be a paradigm-shifting development in our understanding of nutrition and cross-organism communication. In animals, mature miRNAs are short oligonucleotides that bind with imperfect complementarity to target sequences in longer RNA molecules including messenger RNAs (mRNAs) ${ }^{2}$. Loaded into proteins known as Argonautes (AGOs) that recruit additional protein constituents of RNA-induced silencing complexes (RISCs) ${ }^{3-5}$, miRNAs may achieve cleavage, translational repression, or sequestration of target molecules, usually resulting in minor post-transcriptional adjustments that fall within the range of normal physiologic variation ${ }^{6}$, although larger effects have also been described.

Milk is a reported potential source of small RNA molecules in the $\operatorname{diet}^{7}$. The nutritional content of milk includes extracellular vesicles, fat globules, and other structures ${ }^{8}$, some of which contain miRNAs ${ }^{9}$. In contrast with plant sources, in which foreign AGO-inferred protection of miRNAs could also preclude uptake and function in mammalian cells, mammalian miRNAs in the diet could be protected by proteins that might function in recipient cells. Baier et al. reported transient increases of two miRNAs, miR-29b-3p and miR-200c-3p, in circulating plasma and peripheral blood mononuclear cells (PBMCs) of human donors who drank bovine milk $^{10}$. In this study of five subjects, blood was drawn at baseline (T0) and at several intervals after milk intake (including T3, T6, T9 and T24). Peak levels of miR-29b and miR-200c were observed at T3 in plasma and at T6 in PBMC. The authors hypothesized that these additional miRNA copies were xenomiRs, supplied by the cow milk as these bovine and human miRNAs are $100 \%$ identical. An alternative hypothesis ${ }^{11}$ suggests that glucose-sensitive endogenous miRNAs, including these two miRNAs ${ }^{12-15}$, could respond to dietary intake.

Considering the tremendous implications of these findings for the xenomiR delivery hypothesis, we approached Baier et al. and offered to profile additional miRNAs. We hypothesized that more data would help to assess the not necessarily mutually exclusive explanations of the original results: xenomiR delivery or endogenous regulation. The authors generously provided a selection of the original samples. We jointly decided to profile miRNAs at baseline and at the reported peak miRNA concentration for each sample type to look for additional alterations in miRNAs. Accordingly, 10 plasma-derived RNA samples (5 subjects at T0 and T3) and 10 PBMC-derived RNA samples (5 subjects at T0 and T6) were assessed with TaqMan medium-density OpenArray technology arrays and individual miRNA qPCR assays. Finally, these data were compared with small RNA sequencing (RNA-seq) results collected from the same study materials by an independent facility.

\section{Materials and methods}

Sample delivery, preparation, and quality control

Plasma samples and PBMC total RNA samples, prepared as previously described during an institutional review board-approved study ${ }^{10}$, were sent to the authors' laboratory by overnight delivery from the University of Nebraska, Lincoln. No identifying information about the donors was provided. Samples included 10 aliquots of T0 and T3 plasma and 10 T0 and T6 PBMC RNA aliquots from the five participants of the initial study ${ }^{10}$. Although the package arrived on time via overnight delivery, the dry ice within had largely sublimated. Plasma RNA was isolated using the Exiqon "miRCURY RNA Isolation Kits - Biofluids" (Product \# 300112) with modifications as previously described ${ }^{16}$. PBMC RNA quantity and quality was checked by NanoDrop spectrophotometer (Thermo Scientific). Selected miRNAs were assessed by individual qPCR assays (see below under "qPCR assays").

\section{OpenArray profiling and data processing}

A custom miRNA OpenArray chip (Thermo Fisher) was designed to detect miRNAs that are consistently found at relatively high abundance in cell-free body fluids such as blood plasma. Features included 220 miRNAs and three non-miRNA small RNAs, RNU44, RNU48, and snRNA U6 (although these are not necessarily suitable references for extracellular RNA). The highly conserved and abundant plant miRNA MIR159a served as a negative control. MIR159a is not expected to be found in mammalian samples, and, if detected, is likely a sign of environmental contaminants ${ }^{17,18}$. As expected, MIR159a did not amplify in any sample.

Sample processing. RNA ( 3 ul plasma RNA or 100 ng PBMC RNA) was reverse-transcribed with the MegaPlex 'A' pool of reverse transcription primers (Thermo Fisher). cDNA was pre-amplified using MegaPlex 'A' primer pools for a cycle number of 14 (plasma) or 12 (PBMC). Pre-amplified material was diluted per manufacturer's protocol and as previously described ${ }^{19}$ and loaded onto the custom TaqMan OpenArray slides by liquid handling robot in the Johns Hopkins DNA Analysis Facility. Quantitative PCR was run for 40 cycles on a QuantStudio instrument.

Data retrieval and analysis. Data including amplification score and relative threshold cycle (Crt) were retrieved using ExpressionSuite software (Thermo Fisher, v1.0.3). Data were analyzed and visualized using Microsoft Excel for Mac 2011, Version 14.5.4, $\mathrm{R}$ version 3.2.1, and the Multiple Experiment Viewer $(\mathrm{MeV}$, Version 10.2, part of the TM4 Microarray Software Suite $)^{20}$.

Data have been deposited with the Gene Expression Omnibus [GEO ${ }^{21,22}$, RRID:SCR_004584] under accession numbers GSE79922 (PBMC) and GSE79960 (plasma).

\section{OpenArray data normalization and analysis}

Raw Crt values were normalized by several methods. For plasma, correction factors were calculated based on the geometric mean of the Crts of 22 relatively invariant features ("GM22") or on Crt of miR-16, a biofluids reference commonly employed in the literature that, while not appropriate in every case, was relatively invariant in these plasma RNA samples. For PBMC, a correction factor was calculated based on the geometric mean of Crt values of 26 features (including the average of U6 readings) that were selected for relatively low variability ("GM26"). A larger number of reference features were selected for the PBMC dataset because of the proportionally larger total number of apparently detected features. A second correction factor was based on the geometric mean of $\mathrm{Crt}$ values for the three non-miRNAs on the array, RNU44, RNU48, and the average of U6, which have been used in previous studies as reference RNAs for intracellular RNA 
expression ("RN3"). Separately, for both plasma and PBMC RNA, quantile normalization was performed, using all RNAs that were detected in at least 9 of 10 samples. Three different adjustments were thus performed for both the plasma and PBMC datasets.

Because of the small number of samples, we performed paired sample t-tests in Microsoft Excel for Mac 2011 v14.5.4 for those miRNAs with complete pre-to-peak sample pairs and considered results potentially significant at $\mathrm{p}<0.01$.

\section{Hierarchical clustering}

Hierarchical clustering of plasma or PBMC data, filtered by amplification score and for detection in 9 of 10 samples, then adjusted or not via the normalization strategies outlined above, was performed with the Multiple Experiment Viewer v10.2. Data were mean-centered across features. Hierarchical clustering was performed for all samples and features using Pearson correlation and average linkage.

\section{RNA stability test}

Isolated RNA (different plasma source from the above) was aliquoted, frozen at $-80 \mathrm{C}$, and then thawed and left at $22 \mathrm{C}$ for 24 , 8 , 4, or 0 hours. Quantitative PCR assays (see below) were then used to assess levels of hsa-miR-16-5p and spiked-in cel-miR-39.

\section{qPCR assays}

Stem-loop reverse transcription quantitative PCR assays ${ }^{23}$ were performed as previously described ${ }^{16}$. Input was normalized by volume ( $3 \mathrm{ul}$ for plasma RNA) or mass ( $33 \mathrm{ng} /$ reaction for PBMC RNA). Assays were ordered from Applied Biosystems/Thermo Fisher, under Inventoried Cat. \# 4427975: hsa-miR-1-3p (002222), hsa-miR-16-5p (000391), hsa-miR-125b-5p (000449), hsa-miR223-3p (002295), hsa-miR-29b-3p (000413), ath-MIR156a (000333), ath-MIR166a (000347), and cel-miR-39 (000200); and ath-MIR167a (000348) under "Made to Order" Cat. \# 4440886.

\section{RNA sequencing data and analysis}

RNA sequencing data (BioProject ID PRJNA307561) were downloaded from the Sequence Read Archive and processed on a local server. Analysis was done with miRge [24, output: raw and rpm counts for human mapping], Chimira release 1 [25, output: raw and normalized by DESeq 2 v3. $2^{26}$ for human and bovine], and Bowtie v1.1.2 [27, RRID:SCR_005476, mapping to human sequences in miRBase $\mathrm{v} 21^{28}$. Sequences were obtained from miRBase v21 for human and bovine comparisons, and milk miRNA profiling data were sought from several previous publications ${ }^{9,29}$.

\section{Results}

Stability of the samples

The packaging of the shipped samples demonstrated marked sublimation of the dry ice. To assess the stability of the samples, PBMC RNA was measured by spectrophotometer and assessed with stem-loop reverse transcription miRNA qPCR assays for miRs$16,-125 \mathrm{~b}$, and -223 . This showed limited evidence of degradation, since the signal from each miRNA was consistent across samples (Table 1) with two exceptions: the zero time point PBMC samples of subjects 4 and 5 amplified 1.9 and 5.8 cycles later, respectively, than the average. There was no indication of general degradation, and it remains unclear whether the two later-amplifying samples were different prior to transport or only after. Plasma stability is less of a concern, since biofluid miRNAs are protected by close association with AGO proteins, whether inside or outside of extracellular vesicles (EVs). Nevertheless, we used qPCR to assess miR-16 stability and that of a spiked-in RNA, cel-miR-39, finding good agreement across samples (Table 1). Furthermore, RNA samples that were placed at room temperature $(22 \mathrm{C})$ for 0 to 24 hours showed no evidence of degradation of an endogenous or a spikedin RNA (Figure 1). We elected to proceed with profiling of all samples, including the two later-amplifying PBMC samples.

\section{Global analyses of plasma or PBMC miRNAs: OpenArray} profiling

Results overview. A total of 223 microRNAs and small RNA controls were assayed by custom qPCR OpenArray, with 134 plasma miRNAs showing amplification in at least 9 of 10 samples. 118 miRNAs were detected in all samples. In RNA from PBMCs, 167 miRNAs amplified in at least 9 of 10 samples, while 135 miRNAs amplified in all samples.

Table 1. qPCR quality control results. Indicated miRNAs from plasma and PBMC were measured by stem-loop qPCR assays to discover any indications of sample degradation during transport. Shown are average $\mathrm{Cq}$ (cycle of quantitation) values across samples as well as standard deviation. For the PBMC samples, removing the two TO outliers from donors 4 and 5 substantially reduced the variability.

\begin{tabular}{|l|l|l|l|l|l|l|}
\hline \multicolumn{3}{|c}{ PLASMA } & \multicolumn{4}{c|}{ PBMC } \\
\hline miRNA & $\begin{array}{l}\text { Avg } \\
\text { Cq }\end{array}$ & SD & miRNA & $\begin{array}{l}\text { Avg } \\
\text { Cq }\end{array}$ & SD & SD-Outliers \\
\hline miR-16 & 21.40 & 0.54 & miR-16 & 22.06 & 2.64 & 1.14 \\
\hline Spike & 19.84 & 0.51 & miR-125b & 32.20 & 2.10 & 0.67 \\
\hline & & & miR-223 & 21.54 & 2.41 & 1.10 \\
\hline
\end{tabular}

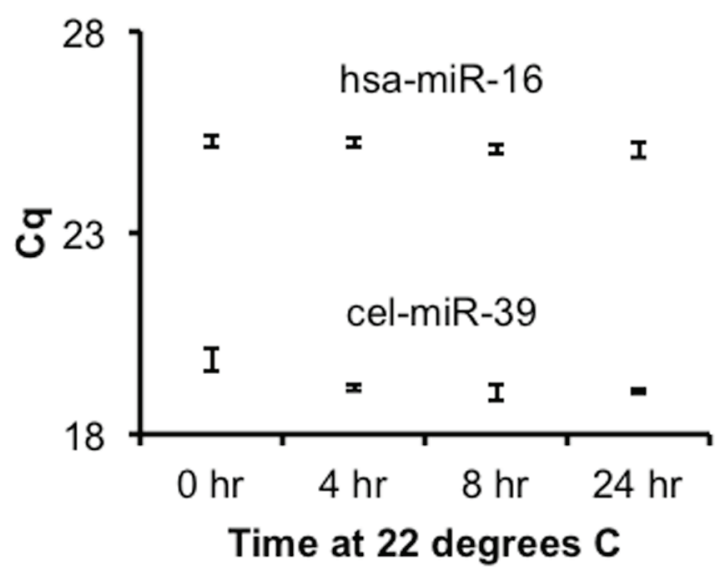

Figure 1. Stability of isolated RNA after thawing. RNA was isolated by the Exiqon Biofluids method from an archived sample of plasma and aliquoted and frozen. Aliquots were thawed and allowed to sit at room temperature (22 C) for 0, 4, 8, or 24 hours. qPCR was used to assess miR-16 and spiked-in cel-miR-39 levels. Shown are $+/-1$ standard deviation for triplicate measurements. 
Analysis criteria. We employed an inclusive approach toward identifying miRNAs that differed between baseline (T0) and peak (either T3 or T6) due to the relatively small number of subjects. No $\mathrm{p}$ value or false discovery rate corrections were performed. Instead, we flagged as potentially interesting those features that: 1) were detected in at least 9 of 10 samples (and thus supplied at least four of a possible five complete T0-to-peak sample pairs); and 2) had an uncorrected $\mathrm{p}$ value by paired t-test of $<0.01$. The same criteria were applied to both plasma and PBMC data.

Plasma miRNA results. As shown in Table 2, no plasma miRNAs fulfilled the above inclusion criteria as being altered by milk intake in the raw dataset. Several miRNAs had a nominally significant $\mathrm{p}$ value in the normalized datasets. However, there was no overlap between the miRNAs identified in the variously normalized data, indicating a lack of robustness of the findings. These arbitrary findings likely represent type 1 error due to the uncorrected $\mathrm{p}$ value cutoff. Furthermore, the average fold change for each feature was less than two fold, with a maximum average upregulation of $92 \%$ and a maximum downregulation of $36 \%$.

PBMC miRNA results. In the PBMC dataset, miR-142-3p was identified in the quantile-normalized dataset, but was not identified under any other normalization strategy (Table 2). Again, this likely represented type I error. No other miRNAs that differed between time points were identified including those previously evaluated (miR-200c, miR-29b, miR-1) ${ }^{1}$. Our lack of finding any additionally variant miRNAs due to milk feeding and our inability to replicate the prior study led us to further examine miR-29b and miR-200c.

Individual analyses of miR-29b and miR-200c

It is possible that expression changes would not reach statistical significance but could still provide some support for the uptake hypothesis, for example, if small increases occurred consistently in all sample pairs or if large but variable fold changes were observed. Therefore, we examined the data for miR-29b and miR-200c for any trends.
Plasma miR-29b. In plasma samples, miR-29b did not amplify consistently and did not satisfy our inclusion criteria above ( $\mathrm{Crt}$ for only 7 of 10 samples and three complete sample pairs). When we examined these values individually, there was no evidence for intake-related increases. miR-29b appeared to increase slightly for donor 1, but to decrease for donors 2 and 3 (raw values). Following normalization by GM22 or miR-16, there was a decrease in all three complete sample pairs. As for other miRNAs examined, these differences were not statistically significant (Table 3).

Plasma miR-200c. miR-200c-associated signal was detected in all plasma samples. This miRNA experienced a slight average downregulation from 0 to 3 hours by 15 to $40 \%$ depending on normalization. Although downregulation was observed in four sample pairs (normalized data) or three (raw data), no changes were significant by paired t-test (Table 3 ).

PBMC miR-29b and miR-200c. For PBMC samples, the raw miR-29b and miR-200c signals were upregulated by $67 \%$ and $93 \%$, respectively, on average (Table 3). These changes were driven by the donor 4 and 5 T0 samples, which quality control had already identified as having abnormally high $\mathrm{Cq}$ values. Following normalization, miR-29b and miR-200c became slightly downregulated.

\section{Hierarchical clustering reveals within-donor relationships}

Hierarchical clustering was performed to find possible milk-intakerelated patterns that were potentially consistent with relationships between samples obtained at the same time points (baseline versus peak) for the entire miRNA dataset. For raw, unadjusted plasma data, samples clustered by donor, not by time point (Figure 2A). After normalization, no consistent pattern (time point or individual) remained (Figure 2B; shown is analysis of quantile-normalized data; similar results were obtained from otherwise normalized data, not shown). Similar results were also seen for PBMC data (Figure 3; as above, results from only raw and quantile-normalized data are shown).

Table 2. miRNAs with uncorrected $p<0.01$ in plasma and PBMC samples

(OpenArray). Shown are miRNAs that satisfied an arbitrary uncorrected $p$ value ("uncorr. p") of 0.01 by two-tailed paired t-test, in data normalized variously for plasma: none, GM22 (geometric mean of 22 invariant features), 16 (miR-16), and QN (quantile normalization); and for PBMC: none, GM26 (geometric mean of 26 invariant features), RN3 (geometric mean of U6, RNU44, and RNU48), and QN (quantile normalization). Average fold change (avg FC) across donors is also shown.

\begin{tabular}{|l|l|l|l|l|l|l|l|l|}
\hline \multicolumn{4}{|c|}{ PLASMA } & \multicolumn{5}{c|}{ PBMC } \\
\hline Norm & miRNA & Uncorr. $\mathbf{p}$ & $\begin{array}{l}\text { avg } \\
\text { FC }\end{array}$ & Norm & miRNA & Uncorr. p & $\begin{array}{l}\text { avg } \\
\text { FC }\end{array}$ \\
\hline None & None & & & None & None & & \\
\hline GM22 & miR-636 & 0.003 & 0.69 & GM26 & None & & \\
\hline & miR-92a & 0.004 & 0.69 & & & & \\
\hline 16 & miR-132 & 0.002 & 1.73 & RN3 & None & & \\
\hline & miR-140 & 0.007 & 1.92 & & & & 1.4 \\
\hline QN & miR-184 & 0.005 & 0.64 & QN & miR-142-3p & 0.005 & \\
\hline
\end{tabular}


Table 3. miR-29b and miR-200c results in plasma and PBMC samples

(OpenArray). Results are shown for normalization techniques for plasma: none, GM22 (geometric mean of 22 invariant features), 16 (miR-16), and QN (quantile normalization); and for PBMC: none, GM26 (geometric mean of 26 invariant features), RN3 (geometric mean of U6, RNU44, and RNU48), and QN (quantile normalization). "NA" = not applicable (miRNA data did not satisfy inclusion criteria), " $p$ " = p value (two-tailed paired t-test with no corrections), "FC" = fold change.

\begin{tabular}{|c|c|c|c|c|c|c|c|}
\hline \multicolumn{4}{|c|}{ PLASMA } & \multicolumn{4}{|c|}{ PBMC } \\
\hline Norm & miRNA & $p$ & avg FC & Norm & miRNA & $p$ & avg FC \\
\hline None & \multirow{4}{*}{ miR-29b } & \multirow{4}{*}{\multicolumn{2}{|c|}{ NA }} & None & \multirow{4}{*}{ miR-29b } & 0.236 & 1.51 \\
\hline GM22 & & & & GM26 & & 0.331 & 0.69 \\
\hline 16 & & & & RN3 & & 0.175 & 0.57 \\
\hline QN & & & & QN & & 0.469 & 0.86 \\
\hline None & \multirow{4}{*}{$\mathrm{miR}-200 \mathrm{c}$} & 0.652 & 1.09 & None & \multirow{4}{*}{ miR-200c } & 0.050 & 2.3 \\
\hline GM22 & & 0.367 & 0.64 & GM26 & & 0.927 & 0.98 \\
\hline 16 & & 0.756 & 0.86 & RN3 & & 0.763 & 0.92 \\
\hline QN & & 0.277 & 0.61 & QN & & 0.756 & 0.95 \\
\hline
\end{tabular}

\section{A}
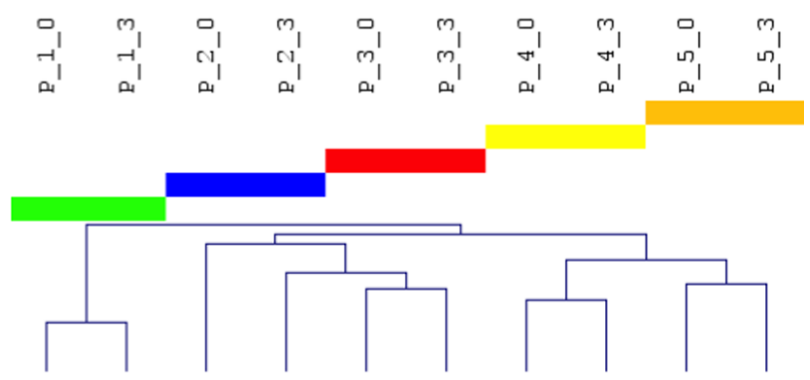

B

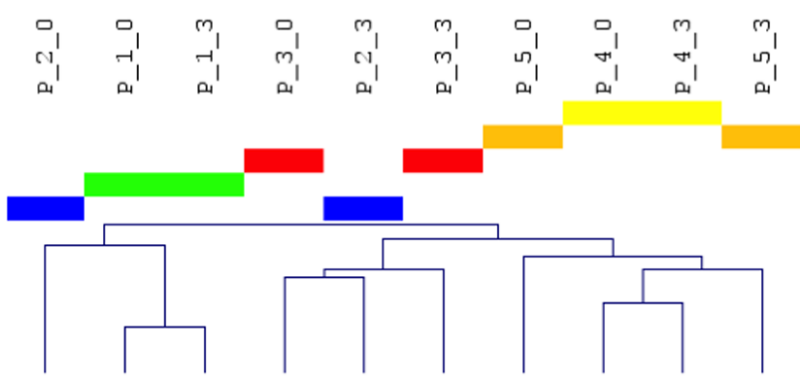

Figure 2. Relationships of plasma samples at T0 and T3. Hierarchical clustering was performed by Pearson correlation and average linkage and conducted for all features from TO and T3 (previously reported peak of milk-derived RNA expression) using raw data $(\mathbf{A})$ or quantile-normalized data $(\mathbf{B})$ from OpenArray profiling of miRNA. Sample notation "P_1_0" indicates plasma, donor 1, at the $0 \mathrm{hr}$ time point. Each color represents one donor.

Individual quantitative PCR assays suggest negligible levels of miR-29b in plasma samples

It is possible that some array-based assays may be less sensitive than standard, higher-volume qPCR assays (10-25 microliters) because of input RNA volume differences. In particular, miR-29b was not detected in all samples, so trends may have been missed. To gather more data on miR-29b if possible, we used individual qPCR

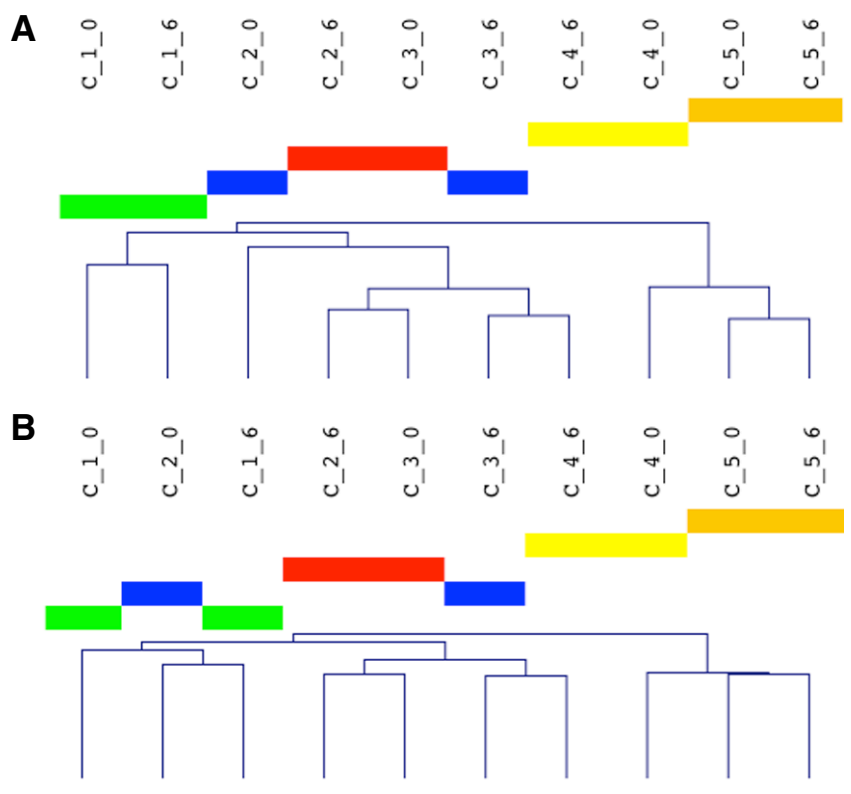

Figure 3. Relationships of PBMC samples at T0 and T6. Sample notation "C_1_0" means cellular (PBMC) RNA, donor 1, at the $0 \mathrm{hr}$ time point. Hierarchical clustering of $\operatorname{raw}(\mathbf{A})$ and quantile-normalized data $(\mathbf{B})$ are shown.

assays to probe miR-29b expression and that of known high- and low-expressed miRNAs (miRs-16 and -1). As negative controls, we measured several foreign RNAs (plant miRNAs MIR156a, 166a, and 167a) that are expected to be present negligibly if at all in human plasma. (Also, plant miRNAs are probably not found in $\mathrm{milk}^{30}$.)

Control miRNAs. Cq values for miR-16, often used as a control in circulating miRNA studies, were fairly stable across samples, 
with no obvious pattern of alteration following milk intake (Figure 4A and Table 1). Only one group of technical triplicates (subject 2, T3) displayed standard deviation of $>0.4 \mathrm{Cq}(\mathrm{CqSD})$. A miRNA normally found at low levels in circulation is miR-1. This largely cardiac and skeletal muscle-specific miRNA may serve as a reliable biomarker of muscle injury precisely because of its normally low abundance in blood ${ }^{31}$. The low abundance and late detection (all $\mathrm{Cq}>32$ ) of miR-1 contributed to large variation in readings even between technical replicates (Figure 4A, most CqSD > 0.4).

Low miR-29b signal. miR-29b was associated with amplification at even higher $\mathrm{Cq}$ values than miR-1, with most replicates amplifying after $\mathrm{Cq}$ of 37 and with CqSD $>0.4$ (Figure 4B). miR-29b appears to be present at only very low levels in circulation of these subjects, and its measurement may be subject to the Poisson effect. miR-29b did not appear to change in response to milk intake. Indeed, miR-29b levels are in the same range associated with nonspecific amplification, as shown by non-specific signals from plant miRNA assays. In these samples, three widely conserved plant miRNAs, MIR156a, MIR167a, and MIR166a, had Cq values almost universally later than 37 and with high variability (Figure 4C).

RNA-seq analysis: independent dataset

Analysis of small RNA-seq data. It remains formally possible that real responses to milk intake were masked in our studies. Varying degrees of partial degradation of samples that we received could have contributed to the lack of significant differences in our OpenArray results. Compromised samples might also explain the failure to detect substantial amounts of miR-29b by individual qPCR. To determine whether sample integrity or technical problems might have biased our results, we found another data source to analyze. We examined a high-throughput small RNA-seq dataset in the Sequence Read Archive (BioProject ID PRJNA307561) ${ }^{32,33}$. In this project, pooled RNA from the same plasma samples we examined was sequenced by an independent facility. The dataset consisted of four pooled samples, representing the five donors at time points 0, 3, 6 and 9 hours post-milk intake. Each sample had between 17.9 and 21 million total reads (Table 4). We analyzed the sample by three methods: miRge ${ }^{24}$, Chimira release $1.0^{25}$, and direct mapping via Bowtie v1.1.2 to mature miRNAs. The percent miRNAs were between 96.6 and $99.1 \%$ for samples at T0, T6, and T9. However, at T3, the $\%$ aligned miRNAs was only $44.9-47 \%$. The dominant miRNA by any measure, representing 43-98\% of all miRNAs in these specimens, was miR-486-5p, a miRNA known to be robustly expressed in red blood cells ${ }^{34}$. Its high level of expression greatly suppressed the RPM counts of all other miRNAs. Despite that, we mapped up to 302 miRNAs, depending on analysis tool and mapping of paralogs. No reads corresponding to miR-29b or miR-200c were detected in any of the samples.

We additionally evaluated the datasets against bovine miRNAs using Chimira. There are 794 known bovine (bta) miRNAs (miRBase v21), some of which do not appear to have homology to human miRNAs. A total of 205 miRNAs matched to this database, including $165,131,138$, and 150 miRNAs at $0,3,6$, and 9 hours. 17 sequences mapped to bta miRNAs without known homologs in humans (Table 5). Of these, only six had ten raw

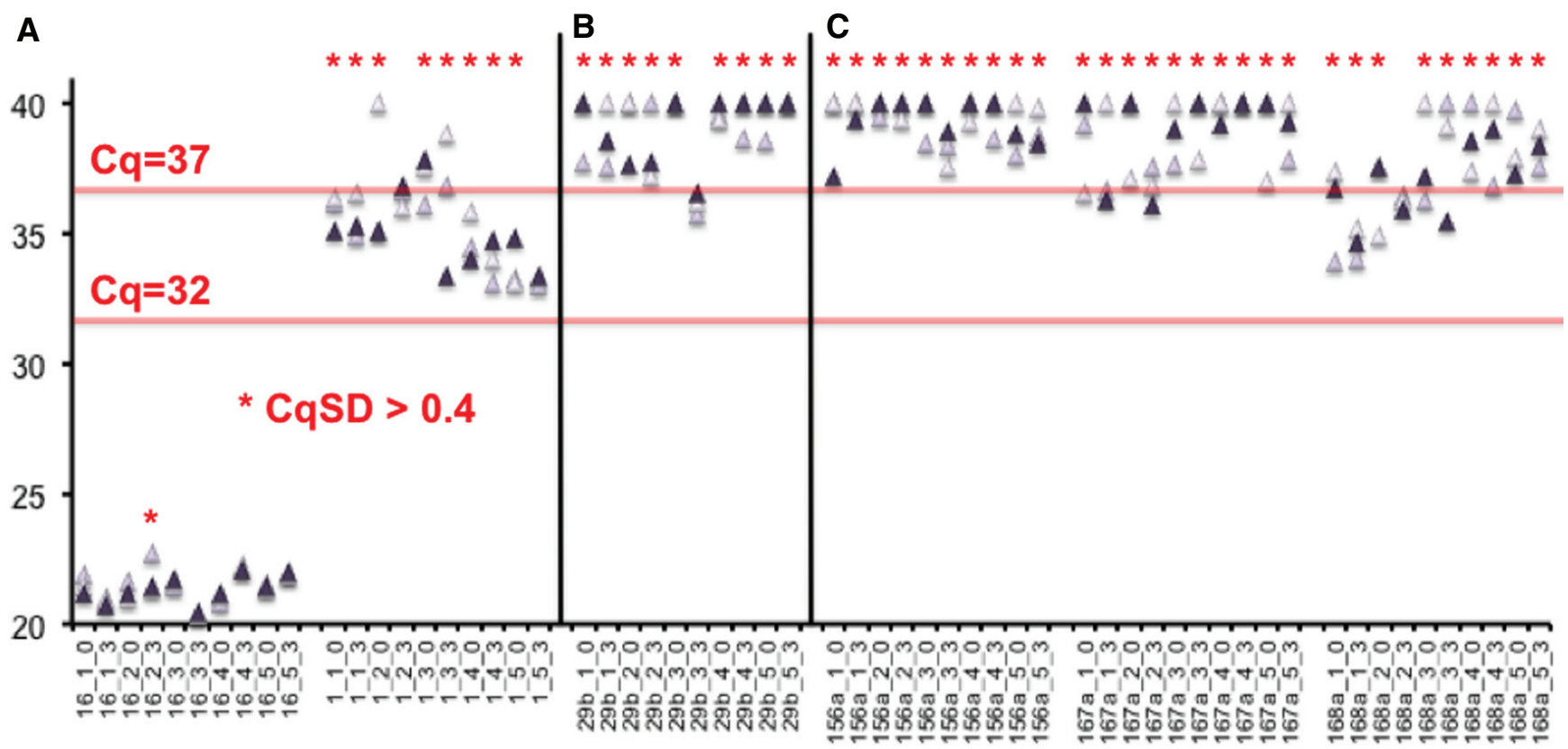

Figure 4. Examples of high, low, and false positive signal detection in plasma RNA samples by quantitative PCR. (A) miR-16 is detected reliably in plasma with $\mathrm{Cq}$ in the low 20s, while miR-1 is detected only in the 30s, with high variability. (B) miR-29b-associated signal is detected only late, with no obvious pattern between pre (0) and post (3) milk intake, and is in the same range as spuriously detected plant miRNA-associated signals (C) for ath-MIR156a, $-166 \mathrm{a}$, and 167a. ${ }^{*}=\mathrm{Cq}$ standard deviation (CqSD) > 0.4. Throughout, the data points are labeled in the format "miRNA_donor_time point", and replicate measurements are indicated by differently shaded symbols. 
counts in at least one sample, and only one, bta-miR-1839, was mapped in all samples. However, bta-miR-1839 was most abundant at T0, inconsistent with derivation from milk. The remaining unique bovine miRNA sequences were distributed in a seemingly random fashion amongst the time points.

Milk abundance versus apparent changes at T3. Since all samples at $0,3,6$, and 9 hours were pooled, expression comparisons cannot strictly be made. Even so, we compared the miRNAs with the greatest apparent fold increase at T3 with previously reported abundance in milk ${ }^{9}$. The top ten increased miRNAs were not found in milk or were not among the most abundant in milk (Table 6). One has no known homolog in cow (hsa-miR-4732-3p). Similarly, the ten miRNAs with the highest reported abundance in milk ${ }^{9}$ experienced apparent decline or increase with no obvious pattern (Table 7). This includes let-7b, the most abundant milk miRNA (40\% of reads) and also among the most enriched in milk exosomes ${ }^{29}$, which appeared to decline $>100$-fold from T0 to T3 (miRge rpm).

Table 4. Mapping percentages by three methods. Total reads in the RNA-seq datasets for plasma at T0, T3, T6, and T9 are shown, along with the number and percentage of reads mapped using miRge, Chimira, or Bowtie.

\begin{tabular}{|l|c|c|c|c|c|c|c|}
\hline & & \multicolumn{2}{|c}{ miRge } & \multicolumn{2}{c}{ Chimira } & \multicolumn{3}{c|}{ Bowtie/miRBase } \\
\hline SRA & Total reads & mapped & $\%$ & mapped & $\%$ & mapped & $\%$ \\
\hline SRR3083757 & 18104234 & 17571674 & 97.1 & 17523557 & 96.8 & 17490252 & 96.6 \\
\hline SRR3083758 & 21050196 & 9898504 & 47.0 & 9688895 & 46.0 & 9442374 & 44.9 \\
\hline SRR3083759 & 17972585 & 17661827 & 98.3 & 17620217 & 98.0 & 17593830 & 97.9 \\
\hline SRR3083760 & 19298056 & 19119013 & 99.1 & 19074396 & 98.8 & 19065638 & 98.8 \\
\hline
\end{tabular}

\section{Table 5. Putative bovine-specific}

miRNAs. Chimira was used to map known bovine miRNAs in RNA-seq data. The miRNAs in this table do not appear to have human homologs. Shown are raw counts at the indicated time points.

\begin{tabular}{|l|r|r|r|r|}
\hline miRNA & T0 & T3 & T6 & T9 \\
\hline bta-mir-1839 & 1333 & 5 & 816 & 157 \\
\hline bta-mir-2338 & & 1 & 698 & \\
\hline bta-mir-2451 & 250 & & 1 & \\
\hline bta-mir-2904 & 4 & & & 21 \\
\hline bta-mir-6532 & & 21 & & \\
\hline bta-mir-3956 & 15 & & & \\
\hline bta-mir-3596 & 2 & & 3 & 3 \\
\hline bta-mir-2284z & 2 & 1 & 1 & 1 \\
\hline bta-mir-2887 & 2 & 1 & & 2 \\
\hline bta-mir-2284x & & 1 & 1 & 1 \\
\hline bta-mir-2484 & & 1 & 2 & \\
\hline bta-mir-2285z & & 2 & & 1 \\
\hline bta-mir-2285g & & 3 & & \\
\hline bta-mir-2370-5p & 1 & & & \\
\hline bta-mir-6529b & & 1 & & \\
\hline bta-mir-2892 & & 1 & & \\
\hline bta-mir-1388-5p & & & & 1 \\
\hline
\end{tabular}

Table 6. Comparison of plasma miRNAs with reported abundance in milk. Plasma miRNAs with the greatest apparent increase from T0 to T3 by RNA-seq were compared with their reported abundance in milk. The top two increasing miRNAs were not detected (ND) in the initial milk sequencing study ${ }^{9}$ while another is not found in bovine. The other increasing miRNAs were not among the most abundant in milk.

\begin{tabular}{|l|c|c|}
\hline \multicolumn{3}{|c|}{ Greatest increase, T0 to T3 } \\
\hline miRNA & FC (T0 to T3) & Milk rank (ref 9) \\
\hline 208b-3p & 9891 & ND \\
\hline $126-3 p$ & 3177 & ND \\
\hline $181 b-5 p$ & 242 & 49 \\
\hline $183-5 p$ & 160 & 117 \\
\hline $125 a-5 p$ & 148 & 56 \\
\hline $4732-3 p$ & 117 & ND (human) \\
\hline $181 a-2-3 p$ & 113 & 42 \\
\hline $141-3 p$ & 64 & 91 \\
\hline $423-3 p$ & 54 & 15 \\
\hline $100-5 p$ & 47 & 121 \\
\hline
\end{tabular}




\begin{abstract}
Table 7. Comparison of milk miRNA abundance with fold change from T0 to T3 in plasma. Of the most highly expressed miRNAs in milk ${ }^{9}$, some appeared to decline after milk intake, while others increased " FC" = fold change). let-7d was not detected (ND) in human plasma at the T3 time point.
\end{abstract}

\begin{tabular}{|l|c|c|}
\hline \multicolumn{3}{|c|}{ Top-ranked milk miRNA (ref 9) } \\
\hline miRNA & $\begin{array}{c}\text { \% milk } \\
\text { miRNAs }\end{array}$ & FC (T0 to T3) \\
\hline let-7b & $39.1 \%$ & -111 \\
\hline let-7a/c & $37.0 \%$ & 5 \\
\hline let-7f & $2.8 \%$ & 14 \\
\hline miR-30a & $1.9 \%$ & -39 \\
\hline miR-21 & $1.7 \%$ & 23 \\
\hline miR-99a & $1.7 \%$ & -33 \\
\hline let-7d & $1.4 \%$ & ND (T3) \\
\hline miR-148a & $1.2 \%$ & 32 \\
\hline miR-92a & $1.1 \%$ & 8 \\
\hline miR-30d & $1.0 \%$ & -1144 \\
\hline
\end{tabular}

\section{Discussion}

We attempted to replicate and expand on the report of Baier et al., that milk intake increases presence of bovine miRNAs in human plasma and PBMCs. Instead, we found no evidence to support this position. Based on OpenArray analysis and qPCR, we found no evidence of a spike of miR-29b or miR-200c levels at time points 3 and 6 hours for plasma and PBMC, respectively. Additionally, in a screen of 220 miRNAs with multiple normalization methods, we found no consistent evidence of any other miRNA alterations at these time points. We further evaluated pooled small RNA-seq data from these same samples. There was no evidence of any miR-29b or miR-200c in any of these sequencing libraries at any time points based on analysis by three methods of miRNA quantification, despite very low levels of amplification by OpenArray or qPCR in most of these samples. Finally, we found no evidence of unique bovine miRNAs or consistently elevated levels of human/bovine homologs from 3 to 9 hours that would be consistent with dietary uptake.

Although our findings are at odds with Baier et al., they are in agreement with other recent publications. When mouse pups were fed by wild-type dams or transgenic mice engineered to overexpress miR-30b by approximately an order of magnitude in milk $^{35}$, there were no significant differences in detected miR-30b levels in various organs and blood of nine mice in each group. miR-375 and miR-200c knockout pups experience no significant uptake of these miRNAs from wild-type nursing dams ${ }^{36}$. As the only experiment to date that can easily distinguish endogenous regulation from exogenous uptake, this study must be given great weight.

\section{What could explain the discrepancies?}

Normalization. Baier et al. used a spiked-in RNA as a reference for the plasma miRNA qPCR results. This method does not control for biological variation. Since the spike-in appears to have been used to assign concentrations, the different concentrations in Figure 1 of Baier et al. ${ }^{10}$, could be the result of technical batch effects (see also below) at different time points. Indeed, using this method, the authors have reported miR-29b concentration estimates for bovine milk that appear to range over almost four orders of magnitude, from $20 \mathrm{fmol} / \mathrm{L}$ in skim milk $(0.2 \% \text { fat })^{37}$ to $50 \mathrm{fmol} / \mathrm{L}$ in raw milk, to $150 \mathrm{pmol} / \mathrm{L}$ in $1 \%$ fat milk $^{10}$. For PBMC, an endogenous RNA, U6, was used, but this is not a miRNA, and its suitability as a reference was not established in these samples. We would also caution that normalizing late-amplifying (high $\mathrm{Cq}$ ) features can be misleading.

RNA purification. To obtain RNA from plasma, Baier et al. used the NucleoSpin miRNA plasma kit (Machery-Nagel), whereas we used the Exiqon Biofluids kit. We previously reported that the Biofluids protocol outperformed several other methods ${ }^{16}$, but we have not tested the Machery-Nagel kit. Although the methods might have different recovery efficiencies, it is not clear how this would influence robust findings. Hypothetical RNA purification differences would not affect the PBMC results, since we used the PBMC RNA isolated by Baier et al.

qPCR assay design. The qPCR system used in the original study depends on enzymatic addition of sequences to the target miRNA followed by amplification and detection with a sequence-nonspecific intercalating dye. The assays we used have sequencespecific RT and qPCR forward primers, as well as a partially sequence-specific hydrolysis probe. It is possible that assays for individual miRNAs might have differing abilities to discriminate between closely-related miRNAs such as members of the miR-29 and miR-200 families.

Variation. In Baier et al., the apparent dose- and time-dependence of the results could be within the range of measurement error as no error bars were given. Indeed, establishing less than two-fold expression differences is technically challenging, especially for a small number of samples.

Sample quality. As noted, samples arrived at our laboratory with dry ice largely sublimated. However, as a batch, the data do not indicate poor quality, with the exception of two T0 samples from the PBMC group. Differential degradation of specific samples in transit seems unlikely to have occurred by chance. Thus, these two problematic T0 samples may have been in the same condition in the original study and thereby explain the PBMC miRNA results of Baier et al.

Differential stability of specific molecules in specific samples. One might conjecture that the miRNAs detected in plasma at higher concentrations by Baier et al. after milk intake were in a particularly labile form that may have been more likely to degrade over time in plasma. However, it is unclear how such degradation could have occurred disproportionately in post-intake plasma. 


\section{Are more studies needed?}

Reproduction. An experimental reproduction of the original study might be informative. However, it may be difficult to justify the expense of new studies given that neither our results nor the RNA sequencing echo the original findings. Rigorous transgenic studies have also yielded negative findings ${ }^{35,36}$. From the standpoint of stoichiometry, it is also unclear that sufficient miRNA, e.g., miR-29b, is present in milk to achieve the originally reported levels in blood. Based on reported miRNA concentrations, one can calculate the quantity of milk and efficiency of uptake required to achieve hypothetical human plasma alterations. As noted above, the authors' milk miR-29b estimates have ranged over almost four orders of magnitude ${ }^{10,37}$. The lower concentration $(20 \mathrm{fmol} / \mathrm{L})$ would necessitate $100 \%$ uptake efficiency and stability and at least 75 liters of bolused milk intake to achieve an increase of $300 \mathrm{fmol} / \mathrm{L}$ in blood of an ingesting human. At the highest reported concentration of miR-29b, $150 \mathrm{pmol} / \mathrm{L},>1 \%$ uptake would be needed. This percentage may be unlikely, as other groups have detected no or negligible dietary miRNA content in an in vitro digestion model $^{36}$ or in intestinal material after gavage of massively nonphysiologic quantities of synthetic, modification-stabilized RNA ${ }^{38}$. Even a purportedly positive study of dietary xenomiRs reported a median uptake of just $0.14 \%$ [39, not counting a clearly spurious detection $\left.^{40}\right]$. While further experimentation would provide additional, welcomed data, it may not be justified by current results or theory.

Other studies: delivery mechanisms. In general, there is a need to learn more about packaging and potential transfer of miRNAs and other cargoes in endogenous EVs or protein complexes. Despite interesting in vitro data suggesting transfer of lipophilic dyes from highly concentrated milk EVs to epithelial models ${ }^{41}$, it is not clear that such experiments are relevant to in vivo transfer. In the absence of consistent evidence of xenomiR delivery in vivo, studies of delivery mechanisms specific to xenomiRs and their carriers are not strongly indicated.

Overall conclusion: miRNA profiling by qPCR array and RNA sequencing of plasma and/or PBMC samples from subjects who ingested milk failed to provide support for uptake of bovine miRNAs. Growing evidence casts doubt on the hypothesis of dietary xenomiR transfer to mammals, whether from different kingdoms $\mathrm{s}^{10,18,42,43}$ or related organisms ${ }^{35,36}$. Although several related and interesting research questions remain, their exigency is low, and further research in this area should be justified in terms of deliverables for more pressing health questions. In mammals, dietary miRNAs, along with other ingested molecules, are likely to serve as nutrition, not post-transcriptional regulators.

\section{Data availability}

Array data can be accessed in the NCBI's GEO public repository (RRID:SCR_004584) under accession numbers GSE79922 (PBMC) and GSE79960 (plasma).

Open Science Framework: Dataset: Uptake of dietary milk miRNAs by adult humans: a validation study, doi 10.17605/OSF. IO/M9RQ2 ${ }^{44}$

\section{Author contributions}

KWW conceived of and directed the study. Experiments were performed by ARA and Witwer lab staff, with assistance from the Johns Hopkins University DNA Analysis Facility. Analyses were performed by GV, AL, and KWW. MKH provided direction on analysis of RNA sequencing data. The first draft of the paper was written by KWW, and the manuscript was revised by KWW and MKH. All authors reviewed and consented to the final manuscript.

\section{Competing interests}

No competing interests were disclosed.

\section{Grant information}

This work was supported by start-up funds from the Department of Molecular and Comparative Pathobiology (to KWW).

The funders had no role in study design, data collection and analysis, decision to publish, or preparation of the manuscript.

\section{Acknowledgments}

The authors would like to thank Scott Baier and Janos Zempleni for providing samples from the original study and for helpful discussions. The expert technical assistance of Lauren Ostrenga and members of the Johns Hopkins University Genetic Resources Core Facility/DNA Analysis Facility is gratefully acknowledged. Zezhou Zhao and Dillon C Muth are acknowledged for contributing miRNA stability data.
1. Witwer KW: XenomiRs and miRNA homeostasis in health and disease: Evidence that diet and dietary miRNAs directly and indirectly influence circulating miRNA profiles. RNA Biol. 2012; 9(9): 1147-54. PubMed Abstract | Publisher Full Text | Free Full Text

2. Bartel DP: MicroRNAs: target recognition and regulatory functions. Cell. 2009; 136(2): 215-33.

PubMed Abstract | Publisher Full Text | Free Full Text

3. Hutvágner G, Zamore PD: A microRNA in a multiple-turnover RNAi enzyme complex. Science. 2002; 297(5589): 2056-60. PubMed Abstract | Publisher Full Text
4. Meister G, Landthaler M, Patkaniowska A, et al:: Human Argonaute2 mediates RNA cleavage targeted by miRNAs and siRNAs. Mol Cell. 2004; 15(2): 185-97. PubMed Abstract | Publisher Full Text

5. Farazi TA, Juranek SA, Tuschl T: The growing catalog of small RNAs and their association with distinct Argonaute/Piwi family members. Development. 2008 135(7): 1201-14.

PubMed Abstract | Publisher Full Text

6. Seitz H: Redefining microRNA targets. Curr Biol. 2009; 19(10): 870-3. PubMed Abstract | Publisher Full Text

7. Kosaka $\mathrm{N}$, Izumi $\mathrm{H}$, Sekine $\mathrm{K}$, et al:: microRNA as a new immune-regulatory 
agent in breast milk. Silence. 2010; 1(1): 7.

PubMed Abstract | Publisher Full Text | Free Full Text

8. Zonneveld MI, Brisson AR, van Herwijnen MJ, et al.: Recovery of extracellular vesicles from human breast milk is influenced by sample collection and vesicle isolation procedures. J Extracell Vesicles. 2014; 3: 24215. PubMed Abstract | Publisher Full Text | Free Full Text

9. Chen X, Gao C, Li H, et al.: Identification and characterization of microRNAs in raw milk during different periods of lactation, commercial fluid, and powdered milk products. Cell Res. 2010; 20(10): 1128-37.

PubMed Abstract | Publisher Full Text

10. Baier SR, Nguyen C, Xie F, et al:: MicroRNAs are absorbed in biologically meaningful amounts from nutritionally relevant doses of cow milk and affect gene expression in peripheral blood mononuclear cells, HEK-293 kidney cell cultures, and mouse livers. J Nutr. 2014; 144(10): 1495-500. PubMed Abstract | Publisher Full Text | Free Full Text

11. Witwer KW: Diet-responsive mammalian miRNAs are likely endogenous. J Nutr. 2014; 144(11): 1880-1.

PubMed Abstract | Publisher Full Text

12. He A, Zhu L, Gupta N, et al:: Overexpression of micro ribonucleic acid 29, highly up-regulated in diabetic rats, leads to insulin resistance in 3T3-L1 adipocytes. Mol Endocrinol. 2007; 21(11): 2785-94. PubMed Abstract | Publisher Full Text

13. Bagge A, Clausen TR, Larsen S, et al:: MicroRNA-29a is up-regulated in beta-cells by glucose and decreases glucose-stimulated insulin secretion. Biochem Biophys Res Commun. 2012; 426(2): 266-72. PubMed Abstract | Publisher Full Text

14. Pandey AK, Verma G, Vig S, et al:: miR-29a levels are elevated in the $\mathrm{db} / \mathrm{db}$ mice liver and its overexpression leads to attenuation of insulin action on PEPCK gene expression in HepG2 cells. Mol Cell Endocrinol. 2011; 332(1-2): 125-33. PubMed Abstract | Publisher Full Text

15. Hennessy E, Clynes M, Jeppesen PB, et al.: Identification of microRNAs with a role in glucose stimulated insulin secretion by expression profiling of MIN6 cells. Biochem Biophys Res Commun. 2010; 396(2): 457-62. PubMed Abstract | Publisher Full Text

16. McAlexander MA, Phillips MJ, Witwer KW: Comparison of Methods for miRNA Extraction from Plasma and Quantitative Recovery of RNA from Cerebrospinal Fluid. Front Genet. 2013; 4: 83. PubMed Abstract | Publisher Full Text | Free Full Text

17. Tosar JP, Rovira $\mathrm{C}$, Naya $\mathrm{H}$, et al:: Mining of public sequencing databases supports a non-dietary origin for putative foreign miRNAs: underestimated effects of contamination in NGS. RNA. 2014; 20(6): 754-7. PubMed Abstract | Publisher Full Text | Free Full Text

18. Witwer KW, Hirschi KD: Transfer and functional consequences of dietary microRNAs in vertebrates: concepts in search of corroboration: negative results challenge the hypothesis that dietary xenomiRs cross the gut and regulate genes in ingesting vertebrates, but important questions persist. Bioessays. 2014; 36(4): 394-406.

PubMed Abstract | Publisher Full Text | Free Full Text

19. McCall MN, Baras AS, Crits-Christoph A, et al:: A benchmark for microRNA quantification algorithms using the OpenArray platform. BMC Bioinformatics. 2016; 17(1): 138.

PubMed Abstract | Publisher Full Text | Free Full Text

20. Chu VT, Gottardo R, Raftery AE, et al:: $M e V+R$ : using $M e V$ as a graphical user interface for Bioconductor applications in microarray analysis. Genome Biol. 2008; 9(7): R118.

PubMed Abstract | Publisher Full Text | Free Full Text

21. Edgar R, Domrachev M, Lash AE: Gene Expression Omnibus: NCBI gene expression and hybridization array data repository. Nucleic Acids Res. 2002; 30(1): 207-10.

PubMed Abstract | Publisher Full Text | Free Full Text

22. Clough E, Barrett T: The Gene Expression Omnibus Database. Methods Mol Biol. 2016; 1418: 93-110.

PubMed Abstract | Publisher Full Text

23. Chen C, Ridzon DA, Broomer AJ, et al:: Real-time quantification of microRNAs by stem-loop RT-PCR. Nucleic Acids Res. 2005; 33(20): e179. PubMed Abstract | Publisher Full Text | Free Full Text

24. Baras AS, Mitchell CJ, Myers JR, et al.: miRge - A Multiplexed Method of Processing Small RNA-Seq Data to Determine MicroRNA Entropy. PLoS One. 2015; 10(11): e0143066.

PubMed Abstract | Publisher Full Text | Free Full Text
25. Vitsios DM, Enright AJ: Chimira: analysis of small RNA sequencing data and microRNA modifications. Bioinformatics. 2015; 31(20): 3365-7.

PubMed Abstract | Publisher Full Text | Free Full Text

26. Love MI, Huber W, Anders S: Moderated estimation of fold change and dispersion for RNA-seq data with DESeq2. Genome Biol. 2014; 15(12): 550 . PubMed Abstract | Publisher Full Text | Free Full Text

27. Langmead B, Trapnell C, Pop M, et al.: Ultrafast and memory-efficient alignment of short DNA sequences to the human genome. Genome Biol. BioMed Central; 2009; 10(3): R25.

PubMed Abstract | Publisher Full Text | Free Full Text

28. Kozomara A, Griffiths-Jones S: miRBase: annotating high confidence microRNAs using deep sequencing data. Nucleic Acids Res. 2014; 42(Database issue): D68-73.

PubMed Abstract | Publisher Full Text | Free Full Text

29. Izumi H, Tsuda M, Sato $Y$, et al:: Bovine milk exosomes contain microRNA and mRNA and are taken up by human macrophages. J Dairy Sci. 2015; 98(5): 2920-33.

PubMed Abstract | Publisher Full Text

30. Bağcl C, Allmer J: One Step Forward, Two Steps Back; Xeno-MicroRNAs Reported in Breast Milk Are Artifacts. PLoS One. 2016; 11(1): e0145065. PubMed Abstract | Publisher Full Text | Free Full Text

31. Ai J, Zhang R, Li Y, et al.: Circulating microRNA-1 as a potential nove biomarker for acute myocardial infarction. Biochem Biophys Res Commun. 2010 391(1): 73-7.

PubMed Abstract | Publisher Full Text

32. Shu J, Chiang K, Zempleni J, et al:: Computational Characterization of Exogenous MicroRNAs that Can Be Transferred into Human Circulation. PLoS One. 2015; 10(11): e0140587.

PubMed Abstract | Publisher Full Text | Free Full Text

33. Homo sapiens (ID 307561) - BioProject - NCBI. Reference Source

34. Kent OA, McCall MN, Cornish TC, et al:: Lessons from miR-143/145: the importance of cell-type localization of miRNAs. Nucleic Acids Res. 2014; 42(12): 7528-38.

PubMed Abstract | Publisher Full Text | Free Full Text

35. Laubier J, Castille J, Le Guillou S, et al:: No effect of an elevated miR-30b level in mouse milk on its level in pup tissues. RNA Biol. 2015; 12(1): 26-9. PubMed Abstract | Publisher Full Text | Free Full Text

36. Title AC, Denzler R, Stoffel M: Uptake and Function Studies of Maternal Milkderived MicroRNAs. J Biol Chem. 2015; 290(39): 23680-91.

PubMed Abstract | Publisher Full Text | Free Full Text

37. Howard KM, Jati Kusuma R, Baier SR, et al.: Loss of miRNAs during processing and storage of cow's (Bos taurus) milk. J Agric Food Chem. 2015; 63(2): 588-92. PubMed Abstract | Publisher Full Text | Free Full Text

38. Mlotshwa S, Pruss GJ, MacArthur JL, et al.: A novel chemopreventive strategy based on therapeutic microRNAs produced in plants. Cell Res. 2015; 25(4): $521-4$

PubMed Abstract | Publisher Full Text | Free Full Text

39. Liang $\mathrm{H}$, Zhang S, Fu Z, et al.: Effective detection and quantification of dietetically absorbed plant microRNAs in human plasma. J Nutr Biochem. 2015; 26(5): 505-12.

PubMed Abstract | Publisher Full Text

40. Witwer KW: Contamination or artifacts may explain reports of plant miRNAs in humans. J Nutr Biochem. 2015; 26(12): 1685.

PubMed Abstract | Publisher Full Text

41. Wolf T, Baier SR, Zempleni J: The Intestinal Transport of Bovine Milk Exosomes Is Mediated by Endocytosis in Human Colon Carcinoma Caco-2 Cells and Rat Small Intestinal IEC-6 Cells. J Nutr. 2015; 145(10): 2201-6.

PubMed Abstract | Publisher Full Text | Free Full Text

42. Cottrill KA, Chan SY: Diet-Derived MicroRNAs: Separating the Dream from Reality. microRNA Diagnostics Ther. 2014; 1(1): 46-57. Publisher Full Text

43. Petrick JS, Brower-Toland B, Jackson AL, et al:: Safety assessment of food and feed from biotechnology-derived crops employing RNA-mediated gene regulation to achieve desired traits: a scientific review. Regul Toxicol Pharmacol. 2013; 66(2): 167-76

PubMed Abstract | Publisher Full Text

44. Auerbach AR, Vyas G, Li A, et al.: Dataset: Uptake of dietary milk miRNAs by adult humans: a validation study. Open Science Framework. 2016. Data Source 


\section{Open Peer Review}

\section{Current Peer Review Status:}

\section{Version 1}

Reviewer Report 10 May 2016

https://doi.org/10.5256/f1000research.9200.r13517

(C) 2016 Seitz H. This is an open access peer review report distributed under the terms of the Creative Commons Attribution License, which permits unrestricted use, distribution, and reproduction in any medium, provided the original work is properly cited.

\section{Hervé Seitz}

Institute of Human Genetics (IGH), UPR 1142, French National Center for Scientific Research (CNRS), Montpellier, France

In this article, A. Auerbach and colleagues revisit the published claim that dietary miRNAs can be detected in human blood. Using carefully designed analytical procedures, they show that the original claim was most likely erroneous. Using RNA samples provided by the authors of the initial paper, with various detection techniques and sensitive statistical testing, Auerbach et al. could not find any indication of food-derived miRNAs in human plasma or peripheral blood mononuclear cells. They also provide a simple mathematical demonstration that the proposed miRNA dietary intake would require unrealistic volumes of ingested milk. This is a solid manuscript, which addresses an important issue. I only have minor comments: this manuscript is almost already suitable for indexing.

Minor comment \#1:

End of the first paragraph of page 2 ("[...] although larger effects have also been described"): bibliographical references are needed here (to my knowledge, large effects were only measured after experimental miRNA over-expression - not with endogenous miRNA levels).

\section{Minor comment \#2:}

In paragraph "Sample delivery, preparation, and quality control" (page 2): dry ice was "largely sublimated" (that observation is also reported at various other places in the manuscript). Do the authors mean that dry ice was completely gone? Or were there still some pellets? If the styrofoam box is well insulated, just one solid pellet in the box ensures that the atmosphere inside the box is still at $-80^{\circ} \mathrm{C}$. The authors should at least tell whether RNA solutions were still solid on arrival.

Minor comment \#3:

In paragraph "OpenArray data normalization and analysis" (page 2): 26 features were selected for "relatively low variability". How was this done?

Minor comment \#4:

In paragraph "RNA stability test" (page 3): was cel-miR-39 spiked-in before or after shipping on dry 
ice?

Minor comment \#5:

The only reliably detected bovine miRNA in human blood is bta-miR-1839, but its accumulation dynamics are not compatible with dietary uptake (first sentence of page 10). The authors may wish to be aware that this "miRNA" is most likely a degradation product from an abundant nuclear RNA, SCARNA15. Full-length bovine and human SCARNA15 are not absolutely identical, but that subsequence (AAGGUAGAUAGAACAGGUCUUGUU) is common to the bovine and human sequences.

Competing Interests: No competing interests were disclosed.

\section{I confirm that I have read this submission and believe that I have an appropriate level of expertise to confirm that it is of an acceptable scientific standard.}

Reviewer Report 04 May 2016

https://doi.org/10.5256/f1000research.9200.r13515

(c) 2016 Allmer J. This is an open access peer review report distributed under the terms of the Creative Commons Attribution License, which permits unrestricted use, distribution, and reproduction in any medium, provided the original work is properly cited.

Jens Allmer

Department of Molecular Biology and Genetics, Izmir Institute of Technology, Urla, Turkey

In essence, Auerbach et al. tried to replicate findings by Baier et al. ${ }^{1}$ and were unable to come to the same conclusions.

Starting from the alleged (tbk unreproduced) finding of rice miRNAs in human plasma ${ }^{2}$, a field advocating dietary uptake of xenomiRs and proposing potential regulatory effects has arisen. While the number of studies contesting such findings is rising, it is important that more scrutiny is applied in this context and the study by Auerbach et al. is very important in this context.

One clever analysis in this study is the application of clustering to investigate if there is a patient or time point related effect, or none at all. And as it turns out there rather is a patient than a time point effect.

I fully support their conclusion that no more studies in this area are indicated before some additional fundamentals have been established. E.g.: the uptake efficiencies of naked and packed (pre-)miRNAs. Then downstream process like uptake of (pre-)miRNAs by cells and finally the regulatory effect of these need to be established before any further effort in the area of dietary xenomiRs should be exerted.

\section{Minor Revisions:}

The introduction mentions that 'essential' miRNAs would lead to a paradigm shift, but many cofactors and other metabolites like amino acids and vitamins are essential and can only be acquired 
via food sources. I suggest the statement should be slightly revised and refer more clearly to cross-kingdom communication and less to nutrition.

In Figure 3 the bars marking samples may have a problem in respect to samples 2 and 3 for both panels.

The study by Bagci and Allmer ${ }^{3}$ does not conclude that there are no plant miRNAs in milk, but rather claims that for the particular samples investigated the plant miRNAs that were found are due to contamination.

However far-fetched this may sound, the Cq values above some threshold are, as pointed out, likely spurious, but I believe that this has to become clear from Figure 4, as well; because some may judge the results as incidence for plant miRNAs in human plasma while they were intended to be negative controls. The figure legend could clearly state that results above Cq X are unreliable.

The methodology describing RNA sequencing data analysis is not reproducible in its current form and could be expanded upon.

Baier et al. ${ }^{1}$ provide error bars for most graphs and present the average +/- SEM (=SD/sqrt(n)) for Figure 1 in Table 1. The section variation in the discussion should be revised accordingly.

xeno-miRNA and xenomiR is used in the text, but xeno-microRNA is not and the abbreviation xenomiR was not introduced as such.

\section{Questions:}

Why was no spiking applied to the PBMC samples?

Would it be possible to provide the quality assessment of SRA samples to see whether the sample SRR3083758 with the most reads has a much lower sequencing quality than the other samples? Perhaps there is some problem with the file which prevents its proper processing by some of the tools and, therefore, not the complete data was mapped. This needs some clarification.

\section{References}

1. Baier SR, Nguyen C, Xie F, Wood JR, et al.: MicroRNAs are absorbed in biologically meaningful amounts from nutritionally relevant doses of cow milk and affect gene expression in peripheral blood mononuclear cells, HEK-293 kidney cell cultures, and mouse livers.J Nutr. 2014; 144 (10): 1495-500 PubMed Abstract | Publisher Full Text

2. Zhang L, Hou D, Chen X, Li D, et al.: Exogenous plant MIR168a specifically targets mammalian LDLRAP1: evidence of cross-kingdom regulation by microRNA.Cell Res. 2012; 22 (1): 107-26 PubMed Abstract | Publisher Full Text

3. Bağcı C, Allmer J: One Step Forward, Two Steps Back; Xeno-MicroRNAs Reported in Breast Milk Are Artifacts.PLoS One. 2016; 11 (1): e0145065 PubMed Abstract | Publisher Full Text

Competing Interests: No competing interests were disclosed.

I confirm that I have read this submission and believe that I have an appropriate level of expertise to confirm that it is of an acceptable scientific standard. 
Reviewer Report 29 April 2016

https://doi.org/10.5256/f1000research.9200.r13516

(c) 2016 Blenkiron C. This is an open access peer review report distributed under the terms of the Creative Commons Attribution License, which permits unrestricted use, distribution, and reproduction in any medium, provided the original work is properly cited.

\section{Cherie Blenkiron}

Department of Molecular Medicine and Pathology, University of Auckland, Auckland, New Zealand

Here Auerbach et al report their attempts to validate the data of Baier et al that showed the presence of bovine miRNAs in human plasma samples after ingestion of milk. Baier et al kindly provided the original samples for this study but Auerbach et al were unable to replicate their findings.

This study is presented in a very thorough and logical manner and the techniques used are appropriate. Multiple analyses are performed in their attempts to validate the findings; they do not rely on a single detection technique or normalisation protocol. The discussion points are also well considered.

Clarity could be provided on the following:

1. The content of the OpenArray. I presume that this was biased towards Human miRNAs. Clarification on the number of miRNAs that are conserved in bovine would be valuable for the reader.

2. In the methods, the OpenArray used a preamplification step but the single probes did not. This was not obvious unless the referenced article was accessed and read. This is a point of difference that affects sensitivity between these assays. With preamplification for the single assays, the Ct values would improve for the low abundance miRNAs and the SD lower for replicates also.

3. The discussion comment on use of differing RNA purification methods might be improved by commenting on why the kits cause differences (e.g. ability to dissociate protein aggregates, lyse EVs etc).

4. A couple of typos- ul used instead of $\mu \mathrm{L}$ pages 2 and 3. Also a degree symbol is missing on pg 3 for $22^{\circ} \mathrm{C}$.

In all the authors have presented a well considered and technically robust study that adds further fuel to the debate of cross-species microRNA signaling.

Competing Interests: No competing interests were disclosed.

I confirm that I have read this submission and believe that I have an appropriate level of expertise to confirm that it is of an acceptable scientific standard. 
The benefits of publishing with F1000Research:

- Your article is published within days, with no editorial bias

- You can publish traditional articles, null/negative results, case reports, data notes and more

- The peer review process is transparent and collaborative

- Your article is indexed in PubMed after passing peer review

- Dedicated customer support at every stage

For pre-submission enquiries, contact research@f1000.com 